\title{
Researches on Sketch Teaching Practice of Industrial Design under the Background of Innovation and Startup
}

\author{
Yang Li \\ Department of Art \\ Zhuhai College of Jilin University \\ Zhuhai, China
}

\begin{abstract}
According to the two-year teaching of sketch design, the article analyzes and summarizes the problems encountered during the practice, and teaching philosophy and methods relative to sketch design are used gradually to solve problems, perfect teaching system and raise the design efficiency, which provides methods and practice experience for the cultivation of applied talents for innovation and startup through higher education.
\end{abstract}

Keywords-Sketch design; creative thinking; project teaching

\section{INTRODUCTION}

Going with the over 20-year reform and opening up in China, the design level at home has been gradually accepted by social fields and become a design industrial chain with huge potential. Design has spread to every corner of our life, influencing basic necessities of the life, living styles, advertisement, garment design, environmental art design, industrial design, architectural design, exhibition design, all of them are in pursuit of innovation and breakthrough while developing.

Nowadays, China is in a transformation stage, and the society has entered a time of digital information which marks computers and new media, with the development and spread of AR and VR, the people's feeling, mentality and experience to hypermedia have been changing, facing such a situation, industrial design highlights its strength than ever, industrial products are no longer static or isolated, based on VR, we could create experience spaces of industrial products, with recipients' participation, we could achieve real manmachine interaction. Therefore, modern industrial design is a materialization of modern awareness and psychology, an integration of sensibility and rationality and a creative activity integrating technology, art, economy and society.

In Chinese colleges, first of all, there are no adequate industrial design faculties, mostly original industrial design teachers originate from those who teach fine arts and industrial arts, for most of them were engaged in pure painting such as oil painting, traditional Chinese painting and engraving, so during teaching, excessive attentions are paid to product appearance, yet the nature of industrial design is weakened. Second, industrial design courses in most colleges underline skill training, and more training is done through computer soft operation, yet few attentions are paid to sketch training, which makes it hard to convert design ideas into design drawings, unable to completely show the design conception, therefore, facing such a situation, our theme group has attempted to conduct teaching reforms, introducing the teaching methods and skills relative to sketch design to the teaching so as to cultivate students' abilities of innovative thinking and practice.

\section{REFORM AND PRACTICE OF INDUSTRIAL DESIGN DRIVEN BY SKETCH DESIGN}

Differing from other art design, industrial design is closely related to technologies and economy of a country. In Europe, industrial design generally shows strong cultural deposits and living atmosphere such as Italian furniture design, German traffic tool design, and Swedish household design and so on, the design atmosphere is relatively free, and most designers are freelancers or have private studios of their own such as Bauhaus, Ludwig Mies Van der Rohe, Stark and the like. In North America, industrial product design, typical in the US, is full of commercial atmosphere, which is focused on product strategy, design management and valuing brand images. In Asia, though the industrial product design started late, yet it develops rapidly, especially the design is stressed in teaching; industrial design was opened gradually in colleges in China, which provide guarantees to cultivate applied talents of industrial design and innovation during the transformation stage.

\section{A. Concept of Sketch Design}

Sketch design is a course where through a free-hand sketch, a design including creativity and conception is completely shown within a given time, it contains the creativity and conception process, necessary characters to interpret and presentation of final design plan, forming final product concept.

\section{B. Background of Sketch Teaching Practice}

The teaching results are focused on training students' abilities of creative thinking and practice, which work as a 
bridge between professional basic courses and design courses, with the two courses well connected, students may rapidly be familiar with the design section. In early 2013, our project group surveyed at tens of manufacturers in Guangdong, finding that the demands of the society and enterprises for talents are transforming, that is, it is changing to the demand for independent and innovative designers from initial demand for pure designers. In colleges, industrial modeling design of that time belonged to a newly rising subject, newly opened in colleges, the existing teaching plans and programs lay emphasis on skill training but little on training of creative thinking. Therefore, there is a wide gap that is hard to span over between basic training and professional courses, considering this point, in 2014, our topic group started to renovate the existing industrial design teaching, paying special attentions to cultivate a sketch-based innovative and practical teaching

\section{Core Significance of Sketch Teaching}

Sketch design may intensify the training of creative design and expression with high density within a short time, which doest good to the implementation of creative design of industrial design and formation of quality product concepts; long term sketch design training makes students memorize the creative design and expression, free to operate with the design abilities improved quickly. The sketch design is not only a design method and skill that students should master, but also a professional language tool for designers to communicate, through the sketch training, designers may have their creativity and expression go synchronous, and design languages fluent so that creative design can satisfy clients, delivering design information accurately.

The sketch design connects basic courses and design courses, and it will be used for program design and communication in the follow-up professional courses such as product design, concept design and so on, which is quite important to improve the course teaching quality and ensure the high quality and efficient operation of the whole teaching system.

Going with the social progress and development especially during the transformation stage, industrial design is in face of new topics. Though facing many restricting conditions, designers still have to seek new clues and present creative design, besides, due to rapid renewal of modern products, the R\&D period is becoming shorter and shorter, to rapidly introduce new design products has become a necessary condition to occupy the market. It requires designers and students who major in design to grasp the design methods of sketch design as quickly as they can so as to present the creativities efficiently and quickly, which will do good to the follow-up deeper design and shorten the R\&D period.

\section{Teaching Problems Solved by Sketch Design}

1) Reform the course contents and structure to meet the needs of the time and students' development

This project adds sketch design courses to basic courses, professional basic courses and professional design courses of industrial modeling design, and conducts systematic researches on teaching methods, contents, strategies of the sketch design. Conduct early survey analysis, practical project course analysis, teaching design and teaching according to topics, and establish new teaching plans.

As a training method and means of industrial modeling design, the sketch design is a description of initial design state, a kind of thinking or an abstracted opinion which has forms and structures, and it is a course where designers turn innovative thinking into visualized products. Through the teaching of early theoretical methods, design procedure and skills, students may master the sketch design method quickly and use them in topics efficiently, which will do good to the follow-up deep design and perfection and finally achieve the goal of shortening design period and cultivating applied talents. At the mid-term of teaching, we and cooperative enterprises jointly establish topics, and students are grouped for early investigation to understand the market demand, product concept and background, man-machine interface, product structure, technologies, materials, goals and ages and needs of customers, price and questionnaire and so on, according to the survey results, the sketch design will be presented. After two-stage training, students may fully grasp the project flow, what they have completed is more than the design; it will play a foundation for the future. Specific procedures are given as follows:

- Topic analysis: Start with the information delivered by the topics given by teachers, collect the product information and goal.

- Conduct surveys and raise problems: Start with function, principle man-machine, operation mode, environment, and state and so on and rise thinking to solve problems, evaluate and find the most creative thinking.

- Extend thinking: Apply what they have accumulated in daily life, consider the internal relations between things in life and design topics.

- Predict visual state: predict the overall effect of visual state, create a primary and tough visual state in mind, describing its characteristics.

- Locate feeling: preconceive through design feeling, analyze the feeling, emotion and so on when using topics, and locate the feeling brought by the topics.

- Description through characters: according to the contents mentioned above, establish the main idea and draft design plans.

- According to the design plan, make use of skills of sketch design, complete expression via drafts.

- According to the design, go further and modify, confirm the final details, complete the final effect drawing on computers and end the whole design. 
2) Apply the teaching concepts and methods of sketch design to courses

This project has applied the teaching concepts and methods of sketch design to the teaching of Product Design Presentation Skills and Bionics Design, the Product Design Presentation Skills is professional course at sophomore with 56 hours, and the Bionics Design is a professional design course at junior with 84 hours. Students are specially trained to quickly convert design thinking to design plans, which will help students grasp the whole design procedures and make them be devoted to the design practice, in the meantime, the courses are further closed, and teaching plans of the project have been established.

During teaching, the project group has made full preparations before class, through representation and interpretation of typical cases of famous designers; students are improved in aesthetic judgment and to understand clearly the development clues so as to cultivate the abilities to predict the development trend of design. In addition, to learn how to appreciate concept design is extremely important for designers, in addition to unique creativity, they could brew excellent design works.
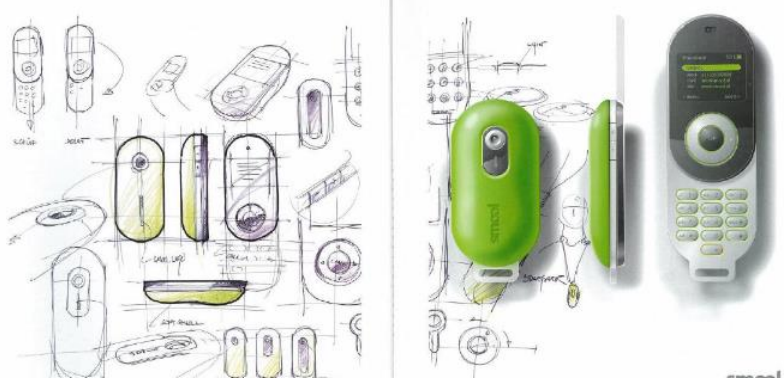

Fig. 1. Quick conversion of sketch to effect drawings

\section{3) Cooperate with enterprises}

This project starts with social needs, the project group and cooperative enterprise (Guangdong Shunke Industrial Co., Ltd) jointly set a topic "Design Changing Life Quality", through early investigation, consumers' psychology evaluation, initial plan, students may complete the final design work according to the sketch design knowledge, and excellent design plans will be selected. During the course, it has not only improve students' abilities of practice, intensified the sketch training but also increased employer's satisfaction, bringing more chances for practice and employment.

\section{4) Innovative thinking training and sketch design} practice

Innovative thinking is a thinking pattern shown during the creativity, which is a three-dimensional and in pursuit of newness, it is not limited to existing orders or opinions, and it tries to expand new fields and clues from different angles and positions so as to get new theories and design methods.

During the sketch design, students are trained to be good at diverse thinking to find the entry point of product design so as to carry out the innovative design or improvement design. Students are trained through image thinking, abstract thinking, divergent thinking, reverse thinking and associative thinking.

During the teaching of expression method, concept design, bionics design and so on, our topic group place the methods and skills of sketch design in the teaching, stressing the sketch practice training. For example, conduct associative and divergent thinking on cooperative topics, it can not only develop students' imagination but also make them see connection between things that look irrelevant, which is just an ability needed for innovation.

\section{E. Value to Apply and Promote the Sketch Teaching}

- As an innovative teaching method and design concept, the results are applied in practical teaching, which have expanded the traditional teaching clues, get the teaching methods optimized, add the contents of sketch design to the bionics design course, according to the knowledge of bionics design course, from the early sketch expression to later completion of effect drawings, students can completely and firmly grasp the design course, the project has been approved to establish "Bionics-based Product Design Teaching Reform and Practice", which play a model and promoting role in the following teaching reform.

- Applying techniques of the project to the product material course, teacher Sun Haijiao, member of the project group, has been approved to establish the "Teaching Reform and Practice of Product Material and Technique Course", which also promotes the teaching reform.

- In the latter half of 2015 , the project leadership and members adopted methods and technique of sketch design to provide art students who take part in the postgraduate entrance exams with intensive training before the exams so as to strengthen their abilities of sketch expression. During the interview of candidates in industrial design, what it is focused on are the abilities of creative design and sketching expression, that is, within a given time, generally 3-6 hours, students are required to complete all tasks given in exam papers through design methods, such as product sketching effect drawing, product design orientation, product creative rough draft, product three views, product color schemes and so on, aiming to check students' comprehensive abilities such as cultural quality, shape building, design innovation, PR, space grouping and so on.

Therefore, the design expression of short time and high efficiency becomes much more important, we conduct intensive training on students who will take part in the postgraduate entrance exams before exams, especially train students in the sketch design method and techniques, based on correct perspective relations, train lines and marker pens, the lines shall be smooth and changing in thickness and virtuality and reality so as to create senses of layering, when coloring with marker pens, pay attention to the color matching, marker pens bring quick colors with strong force, 
it can be properly overlaid, supported by colored pencils for higher visual impact.

During professional interviews, apply techniques of sketch design to sketching so as to complete the drawing quickly, student Fan Xiaodan, studying art at grade 12 was recruited by Guangzhou Academy of Fine Arts to study art for postgraduate degree, student Cheng Qianying was recruited by Macau University of Science and Technology to study art for postgraduate degree, both of them say the training has an apparent effect.

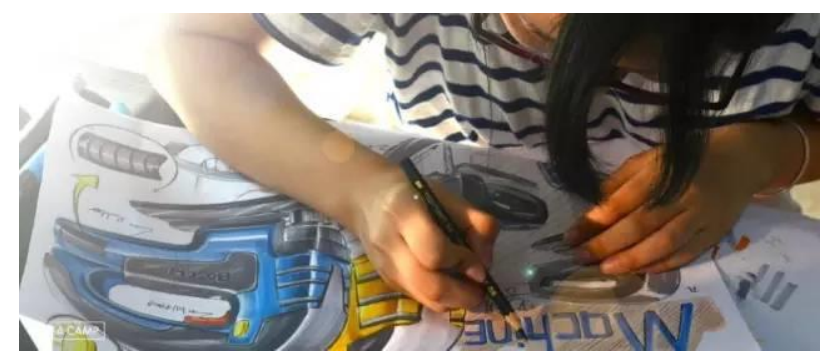

Fig. 2. The training site of students preparing for postgraduate entrance exams

4. Design philosophy of sketch design is adopted to instruct two startup projects Juxiang Art Work Platform and Juanyi Cultural Creativity Co., Ltd established by two college students, currently both of them have owned studios of their own, and the design philosophy of the project is applied and promoted inside and outside the campus.

\section{F. Supporting Data Relative to the Sketch Teaching}

- Teaching Methods and Implementation Strategy of Sketch Teaching, Li Yang, Intelligence, Issue No.14, May 2015.

- Reform Strategy of Product Sketch Design on the Background of Innovation and Startup, Sun Haijiao, Art Education Research (B), Apr 2016.

- Teaching philosophy of this result is used to instruct college reform project "Bionics-based Product Design Teaching Reform and Practice”, Li Yang.

- The project is established to cultivate compound talents in order to meet the needs of innovation and startup, and reforms are conducted upon industrial modeling courses, nature, status quo, social and enterprises' needs. From the initial 56 hours, students have to complete a design within 35 hours, the design period is shortened, which improves students' abilities of combining theories and practice as well as innovative design, The teaching method has obtained distinct teaching effect, having a long term radiation effect.

- The project brings topics to classrooms, the topic group and cooperative enterprises jointly set topics, through specific topic practice, students apply sketch knowledge to complete design plans, which improves enterprises' satisfaction, bringing more chances for students' practice and employment.
- Design technique of the project is used to instruct students who participate in state-level and provinciallevel competitions, winning 3 gold prizes, 4 silver prizes and 7 copper prizes.

\section{CONCLUSION}

Currently colleges are to cultivate innovative and applied talents and the innovative thinking and practical abilities of students are extremely important, and teachers shall not only impart professional knowledge but also cultivate students to set correct morality and values. While conducting product design, students will taste what consumers want psychologically so as to make the products better meet customers, besides, the students are required to value green design, sustainable design and humanization design. During the creative design and sketch conception, what students shall complete are more than a task, a works, instead, they are creating a new life style that are basic literacy for a designer. Therefore, when taught the sketch design, students are also train to understand the basic source of design. Design makes us re-understand the world, creativity is conducted for communication and recognition, and a balance is established through innovative and environment friendly products and meeting the needs of those concerned, and the designers we cultivate are just growing up continuously through unceasingly digging sources of design, and the design level is improved gradually as well.

\section{REFERENCES}

[1] Li Liangjun, Huang Zhaohui, Sketch Design and Expression [M]. Wuhan: Hubei Fine Arts Publishing House, 2009:7.

[2] Lin Hong, Jiang Mu, Discussion on Design Management in Industrial Design [J]. Packaging Engineering, 2011,24:87-90.

[3] Guo Maolai, Xu Jinhong, Yang Yaping et al, Thinking of Industrial Design Teaching [J]. Journal of Jiaxing University, 2014, (11): 111114.

[4] Fu Yingzhe, Discussion on Necessity of Teaching Systematic Structure for Industrial Design [J]. Journal of of Nanjing Institute of Industry Technology, 2015, (3): 57-59. 